\title{
Hereditary cataplexy
}

\author{
JO-ANN M. GELARDI AND JASON W. BROWN ${ }^{1}$
}

In this paper we would like to describe a family with hereditary cataplexy. The condition appears to be transmitted as an unmixed autosomal dominant trait of high penetrance, and, we believe, is the first such example that has found its way into the literature. In compiling the case histories, we have personally examined three members of the family and corresponded extensively with others.

\section{CASE REPORTS}

IV-2 A 24-year-old woman began to have cataplectic attacks at the age of 10 . The attacks occurred only with laughter, lasted only a few seconds, and consisted of marked weakness in the neck muscles with flopping of the head forward or backward, buckling of the knees, opening of the jaw, ptosis, and collapse to the floor. There was no loss of consciousness. With tickling she became helplessly paralyzed, and remained so, even when unable to laugh, so long as the tickling was continued. She denied sleep paralysis, nightmares, hallucinations, or sleep attacks suggestive of narcolepsy. General physical and neurological examinations were unremarkable. An E.E.G. was normal.

IV-3 A 26-year-old male had suffered from laughterinduced cataplexy since the age of 5 years. The attacks have remained unchanged over the years and were identical to, but more severe than, those of his sister. There was no history suggestive of narcolepsy, no sleep paralysis, no nightmares or hallucinations. He also has experienced the same helplessness on tickling as described by his sister.

IV-5 A 17-year-old boy had had cataplexy since the age of 7 years. The attacks consisted of sudden limpness of the arms and legs, drooping of the mouth, eyelids and head, buckling of the knees and collapse to the ground ..., a 'loss of all muscular control'... lasting from a few seconds up to 30 seconds. There was no loss of consciousness. The attacks were precipitated only by laughter, and occurred at an average frequency of one or two per day. There was no effect of crying, surprise, startle, or excitement. The patient also described attacks of sleep paralysis ... 'the same sensation as when laughing '... lasting up to five minutes or more. There was no history of nightmares, hallucinations, or symptoms suggestive of narcolepsy. Neurological examination and E.E.G. were normal.

${ }^{1}$ Formerly of the Division of Neurology, U.C.L.A. Center Health for the Sciences. Reprint requests to 2531 No. Catalina St., Los Angeles, California 90024 (Dr. Brown).
IV-10 For a 27-year-old woman reported to have laughter-induced cataplexy no further history was available.

III-2 A 51-year-old woman began to have laughterinduced drop attacks at the age of 5 years. She reported that over the years she has 'learned to prevent some of the attacks by concentrating on not letting (herself) go.' There was no history of hallucinations, nightmares, or sleep paralysis. Although she napped briefly every afternoon, there were no other symptoms suggestive of narcolepsy.

III-3 A 48-year-old woman had had laughter-induced cataplexy and sleep paralysis since the age of 7 years. The attacks were identical to those described in other members of the family. Both the cataplectic and sleepparalytic attacks have decreased in frequency and severity over the years. There was no history of nightmares, hallucinations, or compulsive sleeping, but she dozed easily when reading or watching television. Neurological examination and E.E.G. were normal.

III-6 A 49-year-old woman began to suffer from cataplexy at the age of 6 years. The attacks were specifically induced by laughing, and, as with the other affected members, have gradually decreased in frequency and severity over the years. There was no history suggestive of narcolepsy; no hallucinations; no sleep paralysis.

III-7 A 38-year-old woman had laughter-induced cataplexy from an early age. She was said to have developed 'epilepsy' and right spastic hemiparesis at an early age, was thought to be mentally retarded, and has been in an institution since the age of 22 .

III-8 A 53-year-old woman had cataplectic attacks beginning between the ages of 5 and 8 years. No further history is available.

II-2 A 75-year-old woman began to suffer from sleep paralysis and cataplexy between the ages of 4 and 8 years. The cataplectic attacks occurred only with laughing and were identical to those described in the other members of the family. By age 30, the attacks were reasonably well controlled and have occurred only occasionally since. There was no history of hallucinations or nightmares, and there were no symptoms to suggest narcolepsy.

II-3 A 70-year-old female, dead of cancer, was reported to have had cataplexy in early life, gradually disappearing as she grew older. Sleep attacks were not described. Further history was unavailable. 


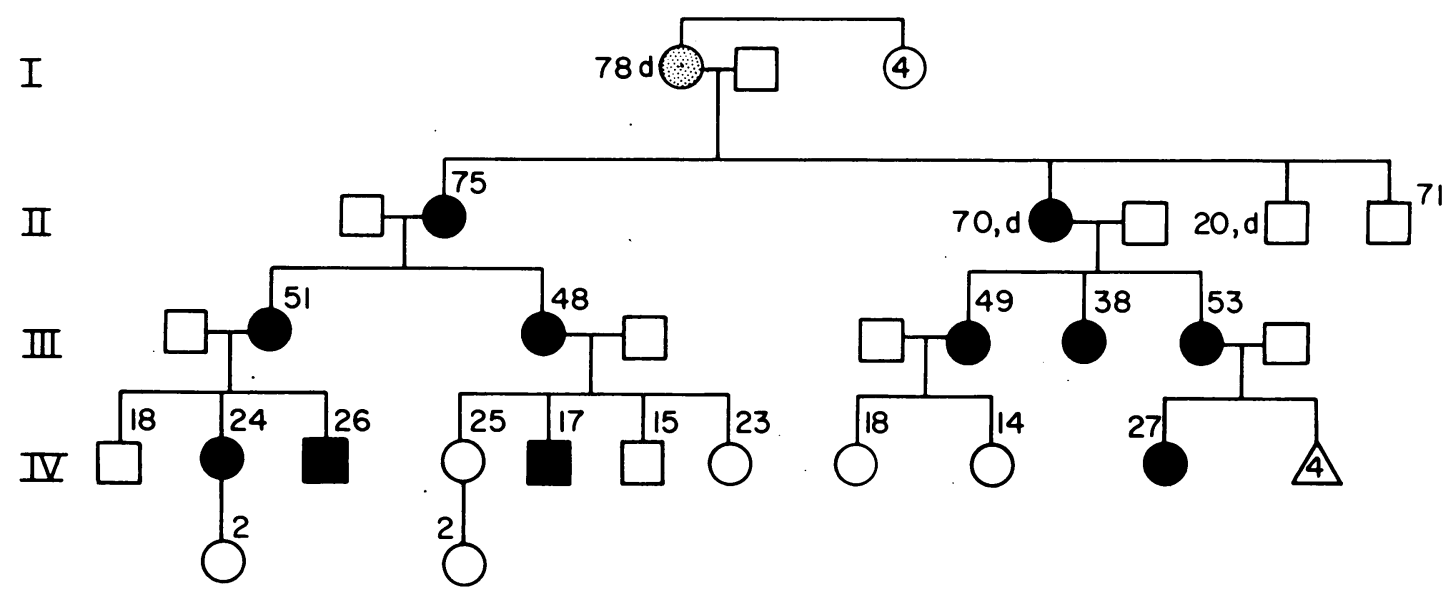

FIG.1. The family tree.

I-1 A 78-year-old woman, dead of cancer, of IrishGerman descent and the product of a first-cousin marriage, was said to have slept easily. She was not recalled to have had cataplectic attacks. No further history available.

\section{COMMENT}

One of the most arresting features of this pedigree (Fig. 1) is the uniformity of the clinical picture from one individual to another and its stability over three generations. The onset is characteristically between the ages of 5 and 8 , with little change into the midtwenties; after age 30 , there occurs a gradual improvement, and the patients report that they 'learn to control' their emotional responses and so prevent further attacks. Whether this is due to a change in the physiology of the disorder, or simply reflects an increasing sobriety with age is not clear.

On no occasion was a clear-cut history of compulsive napping obtained, though three members (III-3, III-2, I-1) were said to fall asleep easily. Hypnagogic hallucinations and/or nightmares were categorically denied. Sleep paralysis was present in three of seven documented cases (IV-5, III-3, II-2). Other aspects of the cataplexy, the early age of onset, the gradual disappearance ('better control') with aging, and the specificity of laughter as precipitant, must be re-emphasized as much for their uniqueness and interest as their theoretical import.

While it is far from clear what relation myopia may have to the inherited cataplectic trait, it seems worthy of mention that all affected, and very few unaffected, members of the family have this fairly severely, in many cases glasses being required before the age of 10. It also appeared that the severity of the myopia was directly proportional to the intensity of the cataplectic attacks. There was no history of diabetes or other familial disease; birth and developmental histories were normal, and intelligence was high.

\section{DISCUSSION}

It is only lately that an hereditary form of narcolepsy has been recognized. Daniels, for example, in his lengthy review of the world's literature up to 1934, was able to uncover but a few cases (Westphal, 1877; Bauer, 1929; Maclagan, 1930; Jakobsohn, 1927; Hoff and Stengel, 1931) considered by him to be fortuitous, in which more than one member of a family was affected. A few years later, Krabbe and Magnussen (1942) described a family in which four of 12 sibs had a somewhat ill-defined sleep disturbance, probably narcolepsy, with no similar disorder in prior or subsequent generations. They were able to find a dozen or so more reports, among which is to be recommended that of Rolandi Ricci (1933), and concluded, accurately perhaps though without apparently consulting the genetics of their own case study, that 'the inheritance... (was) ... connected with a single dominant gene with relatively low penetrative power'. It remained, however, for Daly and Yoss (1959), with a sizeable family spanning four generations and containing 13 proven, three suspect narcoleptics, and Nevšimal and Roth (1958), with a family of eight narcoleptics over three generations, to provide the first well documented and convincing demonstrations of the occurrence of narcolepsy as a strongly penetrant, autosomal dominant trait.

From these studies, the heritability of at least one 
form of narcolepsy would seem assured. However, cataplexy, as an isolated dominant trait, has not been heretofore described. Even in hereditary narcolepsy, cataplectic attacks are infrequently reported, e.g., three of 12 patients in the family of Daly and Yoss had attacks that were uncommonly benign and rare; two of eight patients in the family of Nevšimal and Roth, as compared with an incidence of $67 \%$ in the sporadic form. In the family presented here, the situation is quite clearly reversed, with only three (questionable) instances of narcolepsy in 11 cataplectics. This pattern suggests, of course, that the hypnic and the atonic components of the 'narcoleptic tetrad' may relate to abnormalities in quite distinct genetic and physiological systems.

\section{REFERENCES}

Bauer, J. (1929). Zur Frage der konstitutionellen Minderwertigkeit umschriebenen Hirnbezirke. Wien. med. Wschr., 79, 237-240.

Daly, D. D., and Yoss, R. E. (1959) A family with narcolepsy. Proc. Mayo Clin., 34, 313-319.

Daniels, L. E. (1934). Narcolepsy. Medicine (Baltimore), 13, 1-122.

Hoff, H., and Stengel, E. (1931). Uber familiäre Narkolepsie. Klin. Wschr., 10, 1300-1301.

Jakobsohn, E. (1927). Uber Narkolepsie. Zbl. ges. Neurol. Psychiat., 45, 284-285.

Krabbe, E., and Magnussen, G. (1942). On narcolepsy I. Familial narcolepsy. Acta psychiat. neurol. (Kbh.) 17, 149-173.

Maclagan, E. (1930). Narcolepsy. Proc. roy. Soc. Med., 23, 1406-1407.

Nevišmal, O., and Roth, B. (1958). Př́pad Rodinného Výskytu Narkolepsie (A case of familial incidence of narcolepsy). Csk. Neurol., 21, 54-58.

Rolandi Ricci, P. (1933). Le narcolessie famigliari. Arch. Pat. Clin. med., 13, 43-77.

Westphal, C. (1877). Eigenthümliche mit Einschlafen verbundene Anfälle. Arch. Psychiat. Nervenkr., 7, 631-635. 